\title{
Interpretation of ponded infiltration data using numerical experiments
}

\author{
Michal Dohnal $^{1 *}$, Tomas Vogel ${ }^{1}$, Jaromir Dusek $^{1}$, Jana Votrubova $^{1}$, Miroslav Tesar $^{2}$ \\ ${ }^{1}$ Czech Technical University in Prague, Faculty of Civil Engineering, Thákurova 7, 166 29, Prague, Czech Republic. \\ 2 Institute of Hydrodynamics of the Academy of Sciences of the Czech Republic, Pod Patankou 5, Prague 6, Czech Republic. \\ * Corresponding author. Tel.: +420 22435 5404. E-mail: michal.dohnal@cvut.cz
}

\begin{abstract}
Ponded infiltration experiment is a simple test used for in-situ determination of soil hydraulic properties, particularly saturated hydraulic conductivity and sorptivity. It is known that infiltration process in natural soils is strongly affected by presence of macropores, soil layering, initial and experimental conditions etc. As a result, infiltration record encompasses a complex of mutually compensating effects that are difficult to separate from each other. Determination of sorptivity and saturated hydraulic conductivity from such infiltration data is complicated. In the present study we use numerical simulation to examine the impact of selected experimental conditions and soil profile properties on the ponded infiltration experiment results, specifically in terms of the hydraulic conductivity and sorptivity evaluation. The effect of following factors was considered: depth of ponding, ring insertion depth, initial soil water content, presence of preferential pathways, hydraulic conductivity anisotropy, soil layering, surface layer retention capacity and hydraulic conductivity, and presence of soil pipes or stones under the infiltration ring. Results were compared with a large database of infiltration curves measured at the experimental site Liz (Bohemian Forest, Czech Republic). Reasonably good agreement between simulated and observed infiltration curves was achieved by combining several of factors tested. Moreover, the ring insertion effect was recognized as one of the major causes of uncertainty in the determination of soil hydraulic parameters.
\end{abstract}

Keywords: Ponded infiltration experiment; Two-parameter infiltration equation; Three-dimensional axisymmetric dualcontinuum model; Preferential flow.

\section{INTRODUCTION \\ Methods for the evaluation of ponded infiltration field experiments}

Ponded infiltration experiments, as well as measurements with tension disc infiltrometers, are commonly used field tests for the determination of soil hydraulic conductivity. Ponded infiltration is an extreme case of infiltration which is rarely seen in well-permeable soils under natural field conditions. Nevertheless, the ponded infiltration experiment is a well-established test for the evaluation of soil saturated hydraulic conductivity. It can be performed without a drastic disturbance of the soil surface and has low time and cost requirements. Therefore, it remains popular in the scientific community (Bagarello et al., 2013; Ganz et al., 2014; Hogarth et al., 2013; Wang et al., 2014) and is used in many engineering applications (ASTM Standard D3385-09, 2009).

The field ponded infiltration experiments can be performed in a single- or double-ring configuration (Johnson, 1963). The double-ring infiltration concept has originally been proposed to obtain a one-dimensional character of water flow below the inner ring. However, the flow is not fully one-dimensional for any reasonable diameter of the outer ring, as demonstrated e.g. by Šimůnek (1988) and Dusek et al. (2009). This fact together with a higher water consumption and the uneasy maintenance of equal water levels in both rings makes the double ring configuration impractical for the determination of soil hydraulic parameters.

Advanced techniques based on the inverse solution of Richards' equation were proposed to determine soil hydraulic properties from infiltration experiments. These combine the numerical solution of axisymmetric flow with a nonlinear parameter optimization (e.g., Dohnal et al., 2009; Mirus et al., 2008). On one hand, the numerical inversion of Richards' equation represents a very powerful analytical tool. On the other hand, the numerical inversion of in-situ infiltration experiments was reported to suffer from non-uniqueness due to the lack of information about pressure head, moisture content, or temperature measured (e.g., Nakhaei and Šimůnek, 2014). Probably, for these reasons, a demand for simpler and more robust methods of infiltration experiment data processing persists.

Philip $(1954$; 1957) presented an analytical solution of Richards' equation for one-dimensional infiltration into semiinfinite, homogeneous soil column with uniform initial water content that has a form of infinite time series. For short infiltration times it can be reduced to a simple two-parameter infiltration equation which has become the standard in infiltration data processing:

$I_{1 \mathrm{D}}=S t^{1 / 2}+A t$

$i_{1 \mathrm{D}}=\frac{1}{2} S t^{-1 / 2}+A$

where $I$ is cumulative infiltration rate $(\mathrm{m}), i$ is infiltration rate $\left(\mathrm{m} \mathrm{s}^{-1}\right), t$ is time (s), $S$ is sorptivity of the soil $\left(\mathrm{m} \mathrm{s}^{-1 / 2}\right)$, and $A$ is a coefficient related to the hydraulic conductivity $\left(\mathrm{m} \mathrm{s}^{-1}\right)$. Assuming ponded infiltration of an extensive duration, the infiltration rate finally reaches the value of saturated hydraulic conductivity $K_{s}\left(\mathrm{~m} \mathrm{~s}^{-1}\right)$. Following Miller and Klute (1967), this implies that coefficient $A$ is equal to $K_{s}$. However, considering only short-time infiltration data, the $A$ value obtained by fitting the data with Eq. (2) underestimates the true $K_{s}$.

To evaluate the hydraulic conductivity based on in-situ infiltration experiments, methods considering three-dimensional infiltration process were developed. Smettem et al. (1994), based on the work of Turner and Parlange (1974), established the relationship between the cumulative infiltration rates of $3 \mathrm{D}$ 
infiltration from a circular source of radius $R(\mathrm{~m})$ and the onedimensional infiltration:

$$
I_{3 \mathrm{D}}=I_{1 \mathrm{D}}+\frac{\gamma S^{2}}{R \Delta \theta} t
$$

where $I_{3 \mathrm{D}}(\mathrm{m})$ and $I_{1 \mathrm{D}}(\mathrm{m})$ are the cumulative infiltration rates of the three- and one-dimensional infiltration, respectively, $\gamma$ is a coefficient varying between 0.6 and 0.8 (Haverkamp et al., 1994), and $\Delta \theta\left(\mathrm{m}^{3} \mathrm{~m}^{-3}\right)$ is the difference between the final and initial water contents of the soil. Combining (3) with (1) and (2) provides a simple two-coefficient infiltration formulas of the same form as those for the 1D case, but with different interpretation of the coefficients:

$I_{3 \mathrm{D}}=C_{1} t^{1 / 2}+\left(A+\frac{\gamma S^{2}}{R \Delta \theta}\right) t=C_{1} t^{1 / 2}+C_{2} t$

$i_{3 \mathrm{D}}=\frac{1}{2} C_{1} t^{-1 / 2}+C_{2}$

where $C_{1}\left(\mathrm{~m} \mathrm{~s}^{-1 / 2}\right)$ and $C_{2}\left(\mathrm{~m} \mathrm{~s}^{-1}\right)$ are coefficients related to $S$ and $K$. The coefficients can be determined by fitting Eq. (4) to the measured cumulative infiltration data. This can be done either by direct nonlinear optimization or by one of the linear fitting techniques (e.g., Smiles and Knight, 1976; Vandervaere et al., 1997).

Various methods relating $C_{1}$ and $C_{2}$ to the soil sorptivity $S$ and hydraulic conductivity $K$ have been proposed (e.g. Haverkamp et al., 1994; White and Sully, 1987; Zhang, 1997), but their efficiency is questionable (Dohnal et al., 2010). The analysis of ponded field infiltration experiment is further complicated by several inseparable and possibly mutuallycompensating processes affecting the measured infiltration rate such as soil layering, combination of 1D and 3D flow processes due to infiltration ring insertion (Dusek et al., 2009), preferential flow (Nimmo, 2012), or entrapped air (Wang et al., 1998). Still, $C_{2}$ value determined based on in-situ ponded infiltration experiment is used to evaluate the soil saturated hydraulic conductivity.

The objective of the present study is to analyze various factors affecting measured infiltration rates and thus complicating the interpretation of ponded infiltration experiments. A numerical model of three-dimensional axisymmetric flow is used to identify possible causes of high spatiotemporal variability of measured infiltration curves at a small experimental plot. Following factors were considered: (i) the volume of preferential pathways, (ii) the degree of anisotropy of soil hydraulic conductivity, (iii) the soil layering, (iv) the soil water retention and hydraulic conductivity of the surface organic layer, (v) the presence of soil pipes (caused by soil fauna), and finally (vi) the presence of stone below the infiltration ring. The simulated infiltration curves and the field infiltration data are compared in terms of shape and scale similarities.

\section{MATERIALS AND METHODS Experimental site and soil}

The Liz experimental site is situated in the headwater area of the Volynka River catchment in the Bohemian Forest, southwest Bohemia (total area $0.99 \mathrm{~km}^{2}$, average altitude $941 \mathrm{~m}$ above sea level, average annual precipitation $861 \mathrm{~mm}$, average annual temperature $6.5^{\circ} \mathrm{C}$ ). The prevailing soil type at the experimental site is sandy loam. The soil profile is about $1 \mathrm{~m}$ deep, developed on weathered biotite paragneiss. The soil is classified as Dystric Cambisol. The groundwater table is located about $6 \mathrm{~m}$ below the surface.

The experimental site is located at a meadow surrounded by spruce forest (at a distance of about $50 \mathrm{~m}$ ). The grass is mowed several times a year. The soil profile is affected by the presence of small rodents and other subterranean mammals including shrews or moles. Their activity is clearly visible at the soil surface during the whole year.

\section{Field infiltration experiments}

Since 2003, ponded infiltration experiments have been conducted annually in order to assess the soil hydraulic conductivity and its spatial and temporal variability. The measurements were carried out in a permanent grid of 18 infiltration rings with an average distance between adjacent measurement points equal to $4 \mathrm{~m}$. The internal diameter of the infiltration rings is $37.5 \mathrm{~cm}$, the depth of insertion is about $10 \mathrm{~cm}$. The experiments were performed in summer (July or August). Since 2005, a procedure of repeating the same ponded infiltration experiments in two successive days has been implemented (further on referred to as the $1^{\text {st }}$ and the $2^{\text {nd }}$ infiltration run). Details of the experimental setup and the analysis of the soil infiltrability were presented by Votrubova et al. (2010).

The set of infiltration curves recorded (observed at 18 locations over the period of 11 years) exhibits significant spatial and huge temporal variability (Fig. 1). The infiltration rates measured at Liz are substantially increased due to the presence of preferential pathways. These pathways are associated with various structural soil properties. An important factor contributing to the formation of large macropores, causing strong preferential flow, is the activity of soil fauna.

\section{Numerical model of flow below infiltration ring}

The S2D model (Vogel et al., 2000) of variably saturated soil water flow was used to simulate three-dimensional axisymmetric flow below infiltration rings. The model is based on the dual-continuum concept of Gerke and van Genuchten (1993); the soil is represented by two mutually communicating flow domains - the soil matrix (SM-domain, subscript $m$ ) and the preferential flow domain (PF-domain, subscript $f$ ). The water flow below the infiltration ring is described by a set of two Richards' equations expressed in cylindrical coordinate system:

$$
\begin{aligned}
& C_{m} \frac{\partial h_{m}}{\partial t}=\frac{1}{r} \frac{\partial}{\partial r}\left(r K_{r r}^{m} \frac{\partial h_{m}}{\partial r}\right)+\frac{\partial}{\partial z}\left(K_{z z}^{m} \frac{\partial h_{m}}{\partial z}+K_{z z}^{m}\right)+\frac{\Gamma_{w}}{w_{m}} \\
& C_{f} \frac{\partial h_{f}}{\partial t}=\frac{1}{r} \frac{\partial}{\partial r}\left(r K_{r r}^{f} \frac{\partial h_{f}}{\partial r}\right)+\frac{\partial}{\partial z}\left(K_{z z}^{f} \frac{\partial h_{f}}{\partial z}+K_{z z}^{f}\right)-\frac{\Gamma_{w}}{w_{f}}
\end{aligned}
$$

where $h$ represents the pressure head (m), $K_{r r}$ and $K_{z z}$ are the soil hydraulic conductivities in specified directions $\left(\mathrm{m} \mathrm{s}^{-1}\right), C$ is the differential soil water capacity $\left(\mathrm{m}^{-1}\right), r$ is radial coordinate $(\mathrm{m}), z$ the vertical coordinate taken positive upward ( $z$ coincides with the axis of symmetry), $t$ denotes time (s), $w_{f}$ is the relative volumetric proportion of the preferential domain, $w_{m}=1-w_{f}$, and $\Gamma_{w}$ is the water transfer term $\left(\mathrm{s}^{-1}\right)$. The formulation accounts for possible soil hydraulic conductivity anisotropy with the principal directions along $z$ and $r$ axes. For isotropic soil, $K_{r r}$ 

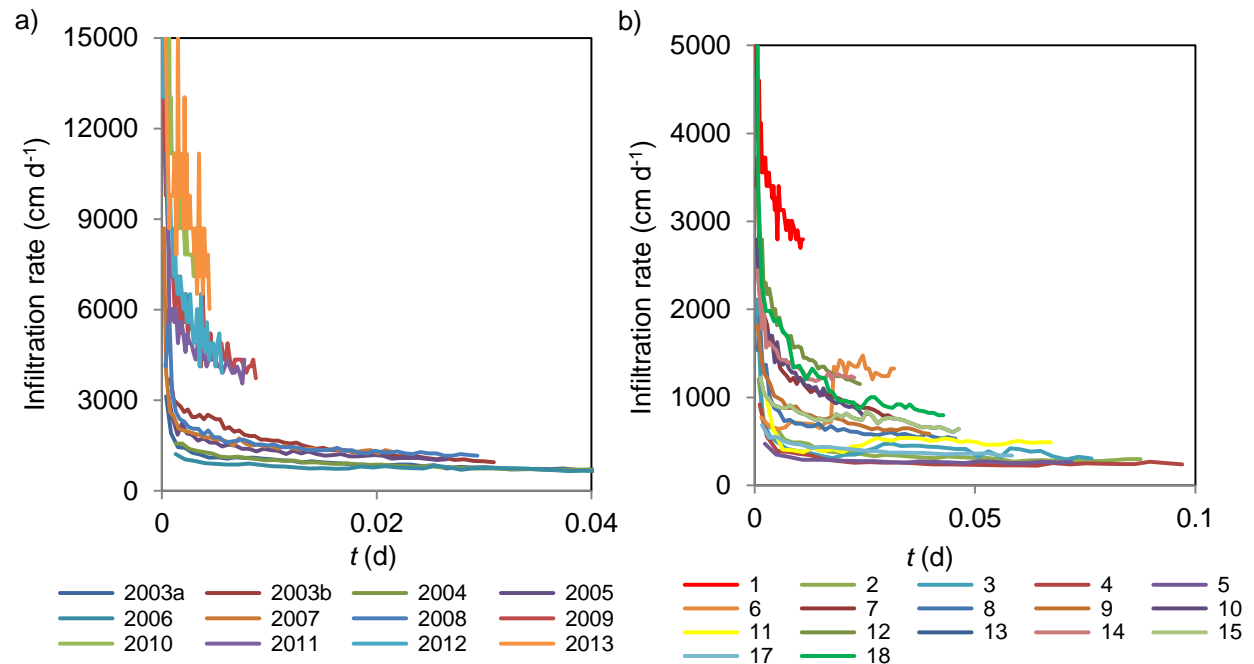

Fig. 1. Temporal and spatial variability of ponded infiltration rates at Liz (a) Infiltration rates measured at one of the 18 permanent infiltration rings over the period 2003-2013 (the $1^{\text {st }}$ infiltration run at ring No. 15); (b) Infiltration rates obtained during one infiltration campaign in summer 2006 (at each of the 18 infiltration rings).

Table 1. Soil hydraulic parameters characterizing the soil profile at Liz (adopted from Votrubova et al., 2012).

\begin{tabular}{llllllll}
\hline Domain & $\begin{array}{l}\text { Depth } \\
(\mathrm{cm})\end{array}$ & $\begin{array}{l}\theta_{r}^{\dagger} \\
(-)\end{array}$ & $\begin{array}{l}\theta_{s} \\
(-)\end{array}$ & $\begin{array}{l}\alpha \\
\left(\mathrm{cm}^{-1}\right)\end{array}$ & $\begin{array}{l}n \\
(-)\end{array}$ & $\begin{array}{l}K_{s} \\
\left(\mathrm{~cm} \mathrm{~d}^{-1}\right)\end{array}$ & $\begin{array}{l}h_{\mathrm{s}} \\
(\mathrm{cm})\end{array}$ \\
\hline SM & $0-10$ & 0.36 & 0.62 & 0.050 & 2.00 & 100.0 & 0.0 \\
& $10-20$ & $0.25^{*+}$ & $0.45^{*+}$ & $0.016^{*+}$ & $1.49^{*+}$ & $3.0^{*}$ & $-3.5^{*+}$ \\
& $20-35$ & 0.24 & 0.42 & 0.022 & 1.45 & 2.5 & -3.2 \\
& $35-50$ & 0.15 & 0.39 & 0.024 & 1.25 & 2.5 & -2.1 \\
& $50-100$ & 0.19 & 0.39 & 0.011 & 1.59 & 2.0 & -2.1 \\
& $100-300$ & 0.07 & 0.27 & 0.060 & 1.48 & 0.5 & -1.1 \\
\hline PF & $0-10$ & 0.05 & 0.43 & 0.144 & 2.68 & 2000 & 0.0 \\
& $10-300$ & $0.05^{*}$ & $0.43^{*}$ & $0.144^{*}$ & $2.68^{*}$ & $1000^{*}$ & $0.0^{*}$ \\
\hline
\end{tabular}

${ }^{\dagger} \theta_{r}$ and $\theta_{s}$ are the residual and saturated soil water contents, $K_{s}$ is the saturated hydraulic conductivity, $h_{s}$ is the air-entry value, and $\alpha$ and $n$ are empirical parameters, determining the shape of retention function.

*SM and PF parameters of the second layer were used for dual-continuum simulations for homogeneous soil profile scenarios

${ }^{+} \mathrm{SM}$ parameters of the second layer were used for single-continuum simulations for homogeneous soil profile scenarios assuming saturated hydraulic conductivity $K_{s}=205 \mathrm{~cm} \mathrm{~d}^{-1}$.

equals $K_{z z}$. The transfer term facilitates the exchange of water between both flow domains. A first order approximation of the water transfer term proportional to pressure head difference between domains is used. The soil hydraulic properties are described with the modified van Genuchten expressions (van Genuchten, 1980; Vogel et al., 2001).

The S2D model was used to simulate soil water flow inside and beneath a single ring and to generate infiltration rates. The soil hydraulic parameters used in simulations are listed in Table 1 . The generated infiltration rates were treated as synthetic infiltration data in the subsequent analysis (i.e., they were approximated by Eq. (4) and plotted in a linearized projection to facilitate the comparison with the measured infiltration curves).

\section{Numerical experiments}

The flow domain used in simulations was symmetric along the infiltration ring axis. The domain was $200 \mathrm{~cm}$ wide and
$300 \mathrm{~cm}$ deep (a larger domain was used for numerical experiments with enhanced anisotropy). Dirichlet boundary condition prescribing constant pressure head was used for the flooded area of the infiltration ring. Neumann boundary condition forcing unit hydraulic gradient was applied at the bottom boundary. All other boundaries were treated as zero flux boundaries (Neumann boundary condition). A constant pressure head was assumed in the entire flow domain as the initial condition. The numerical experiment setup is depicted in Fig. 2. An optional internal boundary was used to model a sink hole of infinite capacity (e.g., due to the presence of soil pipes) or a flat stone. The sink hole was modeled using the seepage face boundary condition (switching between Neumann and Dirichlet boundary condition). For the flat stone, zero flux across boundary was used. The diameter of the embedded structure, $E$, was 16 or $23 \mathrm{~cm}$ which corresponds to the sink hole/flat stone covering 20 or 42 percent of the infiltration ring area. 


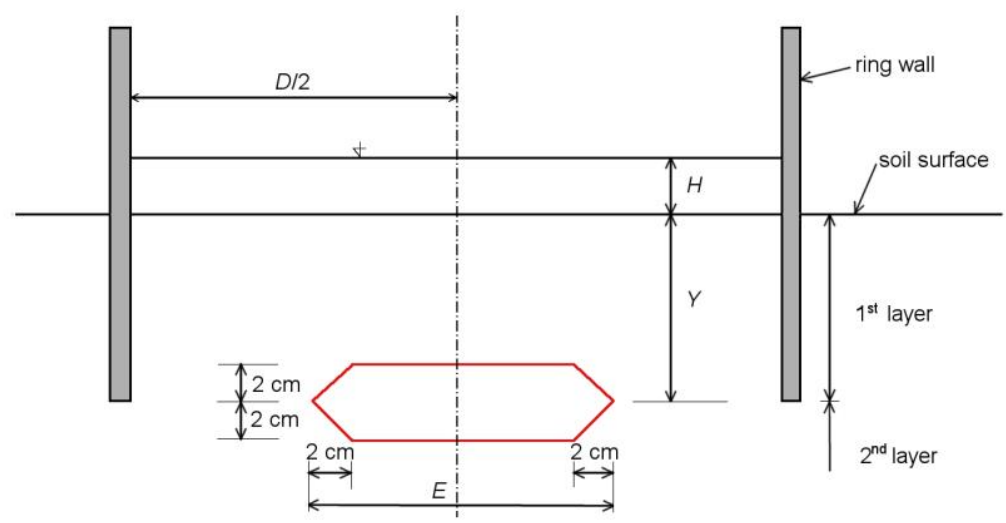

Fig. 2. The single-ring infiltration experiment setup including the optional internal boundary (red line) representing either a sink hole or a flat stone: $D$ is the ring diameter ( $35.7 \mathrm{~cm}$ in our study), $H$ is the depth of water in the ring, $Y$ is the depth of the ring insertion under the soil surface, and $E$ is the diameter of the embedded structure.

Table 2. Overview of experimental conditions combined in numerical experiments.

\begin{tabular}{|c|c|c|c|c|}
\hline 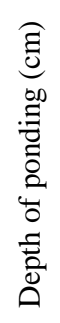 & 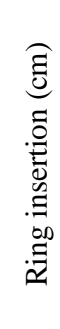 & 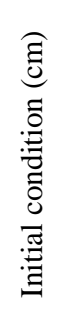 & 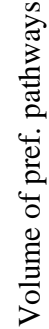 & 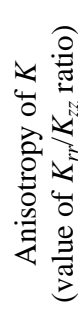 \\
\hline
\end{tabular}

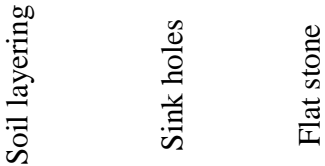

\begin{tabular}{|c|c|c|c|c|c|c|c|c|c|}
\hline Depth of ponding $(\mathrm{cm})$ & varied & 10 & -400 & 0 & 1 & - & - & - & - \\
\hline Ring insertion (cm) & 3 & varied & -400 & 0 & 1 & - & - & - & - \\
\hline Initial condition $(\mathrm{cm})$ & 3 & 10 & varied & 0 & 1 & - & - & - & - \\
\hline Volume of pref. pathways & 3 & 10 & -400 & varied & 1 & - & - & - & - \\
\hline $\begin{array}{l}\text { Anisotropy of } K \text { (value of } \\
K_{r r} / K_{z z} \text { ratio) }\end{array}$ & 3 & 10 & -400 & 0 & varied & - & - & - & - \\
\hline $\begin{array}{l}\text { Uncertainty of surface org. } \\
\text { layer properties }\end{array}$ & 3 & 10 & -400 & 0 & 1 & included & - & - & - \\
\hline Soil layering & 3 & 10 & -400 & varied & 1 & - & included & - & - \\
\hline Sink hole & 3 & 10 & -400 & 0.07 & 1 & - & included & varied & - \\
\hline Flat stone & 3 & 10 & -400 & 0.07 & 1 & - & included & - & varied \\
\hline
\end{tabular}

The following factors potentially affecting in-situ ponded infiltration were studied in the respective numerical experiments:

(i) The depth of ponding and the depth of ring insertion $(H=1,3,5$, and $10 \mathrm{~cm}, Y=0,10$, and $20 \mathrm{~cm})$. The partial effects of both factors had been already studied by Dusek et al. (2009). The effects arising from combinations of these two factors with the other factors considered are analyzed in the present study.

(ii) Antecedent moisture condition (pressure head of $-100,-400$, and $-1000 \mathrm{~cm}$ for wet, medium, and dry state of the soil)

(iii) Preferential flow of various extent considering $w_{f}=$ $0.03,0.1,0.2,0.25$, and 0.4 . The fraction of preferential flow domain at Liz, as an important model parameter, is highly variable in both space and time.

(iv) Surface, organic layer properties applying different effective pore volume, i.e. the difference between saturated and residual water contents $(0.2$ and 0.8$)$ and saturated hydraulic conductivity $\left(500,1000\right.$, and $\left.2000 \mathrm{~cm} \mathrm{~d}^{-1}\right)$. Usually, no reliable measurement of hydraulic properties is available for the uppermost turf layer of the soil profile. Moreover, these properties are likely to change in time.

(v) The anisotropy of hydraulic conductivity, i.e. the effect of different $K_{r r} / K_{z z}$ ratios (from 1/100 to 3).

(vi) Soil layering, i.e. the effect of natural soil profile with hydraulically distinct soil layers (Table 1).

(vii) Sink hole below infiltration rings. The experiment is designed to study the effect of networks of burrows associated with rodent activity. Two scenarios (20 and 42 percent of the infiltration area treated as a seepage face boundary) are tested.

(viii) Flat stone below infiltration ring, i.e. the effect of stoniness (20 and 42 percent of the infiltration area treated as a no-flow boundary).

A summary of the numerical experiments is provided in Table 2. In the following paragraphs, the results of these experiments are compared with the infiltration curves measured at Liz. 


\section{Fitting Philip's equation - data projection method}

Infiltration data were visualized and evaluated using: (i) plots of the cumulative infiltration in time, (ii) the instantaneous infiltration rate in time, and (iii) the cumulative infiltration differentiated with respect to the square root of time (linearization according to Vandervaere et al., 1997).

The differentiated linearization method of Vandervaere et al. (1997) is based on the differentiation of Eq. (4):

$$
\frac{\mathrm{d} I}{\mathrm{~d} t^{1 / 2}}=C_{1}+2 C_{2} t^{1 / 2}
$$

It follows from Eq. (8) that a plot of $\frac{\mathrm{d} I}{\mathrm{~d} t^{1 / 2}}$ versus $t^{1 / 2}$ should display a linear relationship (Fig. 3b) with the intercept equal to $C_{1}$ and the slope given by $2 C_{2}$. Fig. $3 \mathrm{~b}$ demonstrates the projection method of Vandervaere on infiltration data from the experimental site Liz. The linearization is well suited for the evaluation of coefficients $C_{1}$ and $C_{2}$. Basically, the fitted line intercept relates to the soil sorptivity and its slope reflects the fitted final infiltration rate (Eqs. (4) and (5)). Visualization using Eq. (8) allows easy inspection of data quality and possibly also of the effects that various experimental conditions have on the infiltration data and consequently on the hydraulic properties estimation.

a)

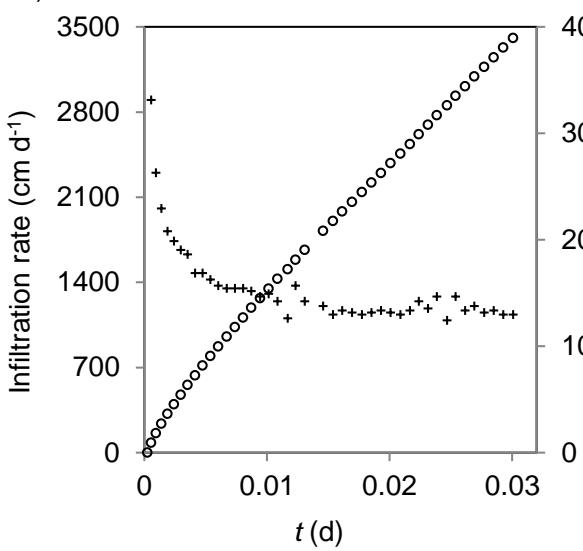

\section{RESULTS AND DISCUSSION Depth of ponding and ring insertion}

It is obvious that a higher water level maintained in the ring produces higher infiltration rates due to a greater pressure gradient. The effect of increasing the depth of ponding, $H$, on linearized infiltration curves is depicted in Fig. 4a. The related changes of the infiltration rate are reflected in varying slopes of the infiltration curves. The distinct bend observed on all curves presented in Fig. 4a relates to the transition from vertical 1D flow within the infiltration ring to 3D flow below the infiltration ring as illustrated in Fig. 5.

This is consistent with results of Dusek et al. (2009) who also suggested that the depth of ring insertion under the soil surface, $Y$, was the most important geometrical factor affecting the character of flow under the infiltration ring. Fig. $4 \mathrm{~b}$ presents simulation results obtained when considering different depths of ring insertion. The case with $Y=0$ represents the "ideal" 3D infiltration experiment considered in Eqs. (4) and (5). It is well known that the steady state infiltration rates for shallow ring insertions are significantly higher than those obtained for deeper insertions (compare the changes of the line slope in Fig. 4b). The impact on the soil saturated hydraulic conductivity estimation is obvious.

b)

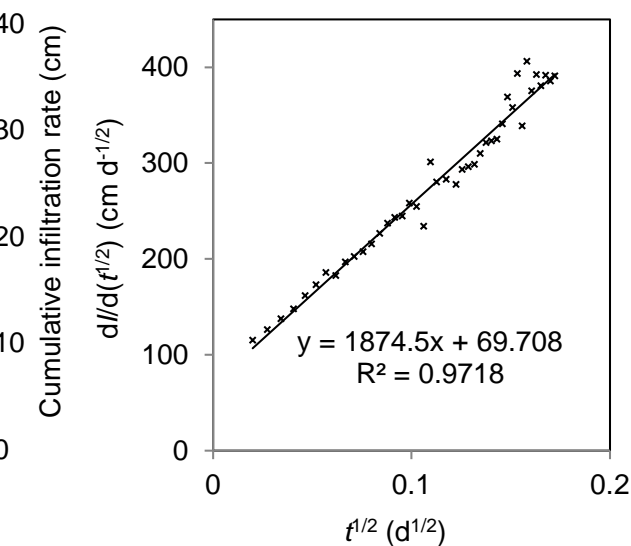

Fig. 3. Infiltration data visualization: (a) measured infiltration rates; (b) linearized data (Eq. (8), i.e., the method of Vandervaere et al., 1997). Ponded infiltration data measured in the ring No. 1 on $4^{\text {th }}$ of August, 2008, are displayed.

a)

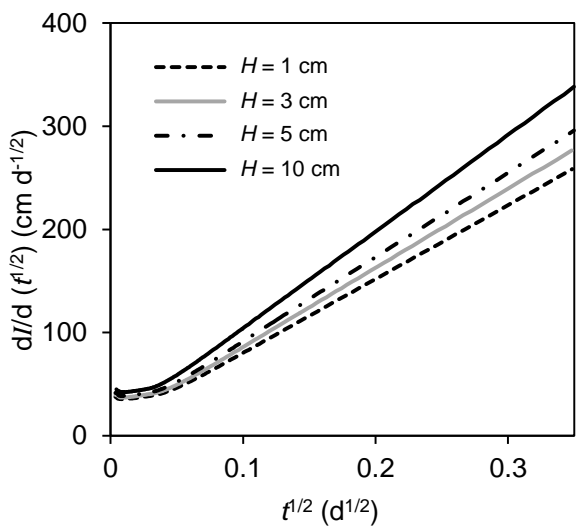

b)

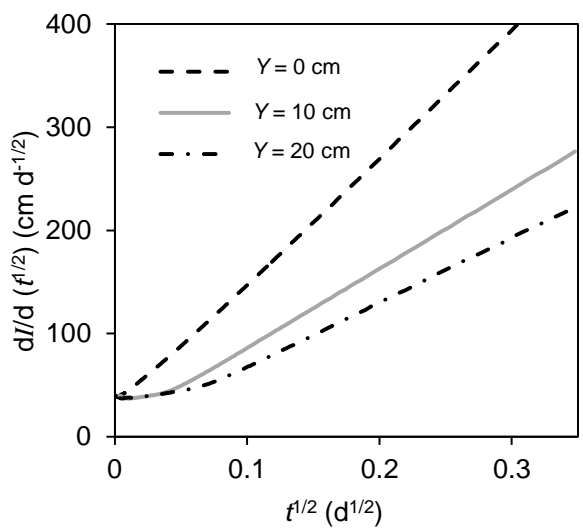

Fig. 4. Simulated infiltration rates assuming (a) four different depth of ponding $H$ and (b) three different ring insertion depths $Y$. 
a)

b)

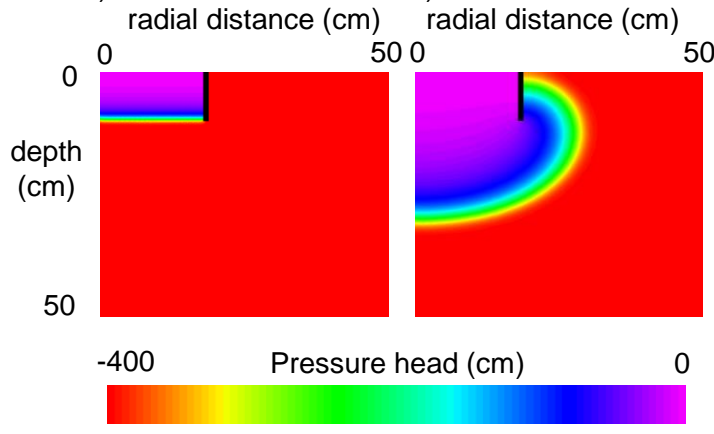

Fig. 5. The $r-z$ cross-section of pressure head field in the flow domain at: (a) $t=1 \mathrm{~min}$, i.e. when the character of flow changes from $1 \mathrm{D}$ to $3 \mathrm{D}$ flow, and (b) $t=10.1 \mathrm{~min}$. Homogeneous soil profile according to soil properties in Table 1 was considered. The depth of the ring insertion was $10 \mathrm{~cm}$, the depth of ponding $3 \mathrm{~cm}$ and initial soil water pressure head $-400 \mathrm{~cm}$.

Fig. 5a shows pressure head field related to vertical 1D flow before wetting front reaches the bottom edge of the infiltration ring. Fully developed 3D water flow below the infiltration ring is shown in Fig. 5 b.

\section{Initial condition}

In theory, the steady state infiltration rate should not depend on antecedent soil water saturation (e.g., Hillel, 1998). Fig. 6a demonstrates that with the simulation model, very similar infiltration rates are achieved after about 40 minutes of infiltrations started from significantly different initial conditions (initial soil water pressure head, $h_{\text {init }}$, set to $-1000 \mathrm{~cm}$ and $-100 \mathrm{~cm}$ ). Accordingly, the fitted $C_{1}$ and $C_{2}$ values (Table 3 ) confirm that the initial water content affects mostly the sorptivity related coefficient $C_{1}$. However, the experimental results from $\mathrm{Liz}$ exhibit a large difference in the quasi-steady state infiltration rate between two subsequent ponded infiltration experiments (the second infiltration starting 21 hours after the first one), Fig. $6 \mathrm{~b}$. The difference in final infiltration rates between the first and second infiltration run was $1083 \mathrm{~cm} \mathrm{~d}^{-1}$ (i.e., $45.1 \mathrm{~cm} \mathrm{~h}^{-1}$ ). Moreover, the infiltration rate during the initial phase of the $2^{\text {nd }}$ infiltration run was similar to the final rate observed during the $1^{\text {st }}$ infiltration run. Such behavior was previously described by Císlerova et al. (1988). The difference in flow rates was hypothesized to be caused by air entrapment. This hypothesis was later supported by numerical modeling of the infiltration process in a laboratory soil column (Dohnal et al., 2013).

Table 3. Coefficients $C_{1}$ and $C_{2}$ determined by fitting Eq. (4) to the synthetic cumulative infiltration data generated in numerical experiments. First and second parts of data are fitted separately when soil layering changes slopes of infiltration curves.

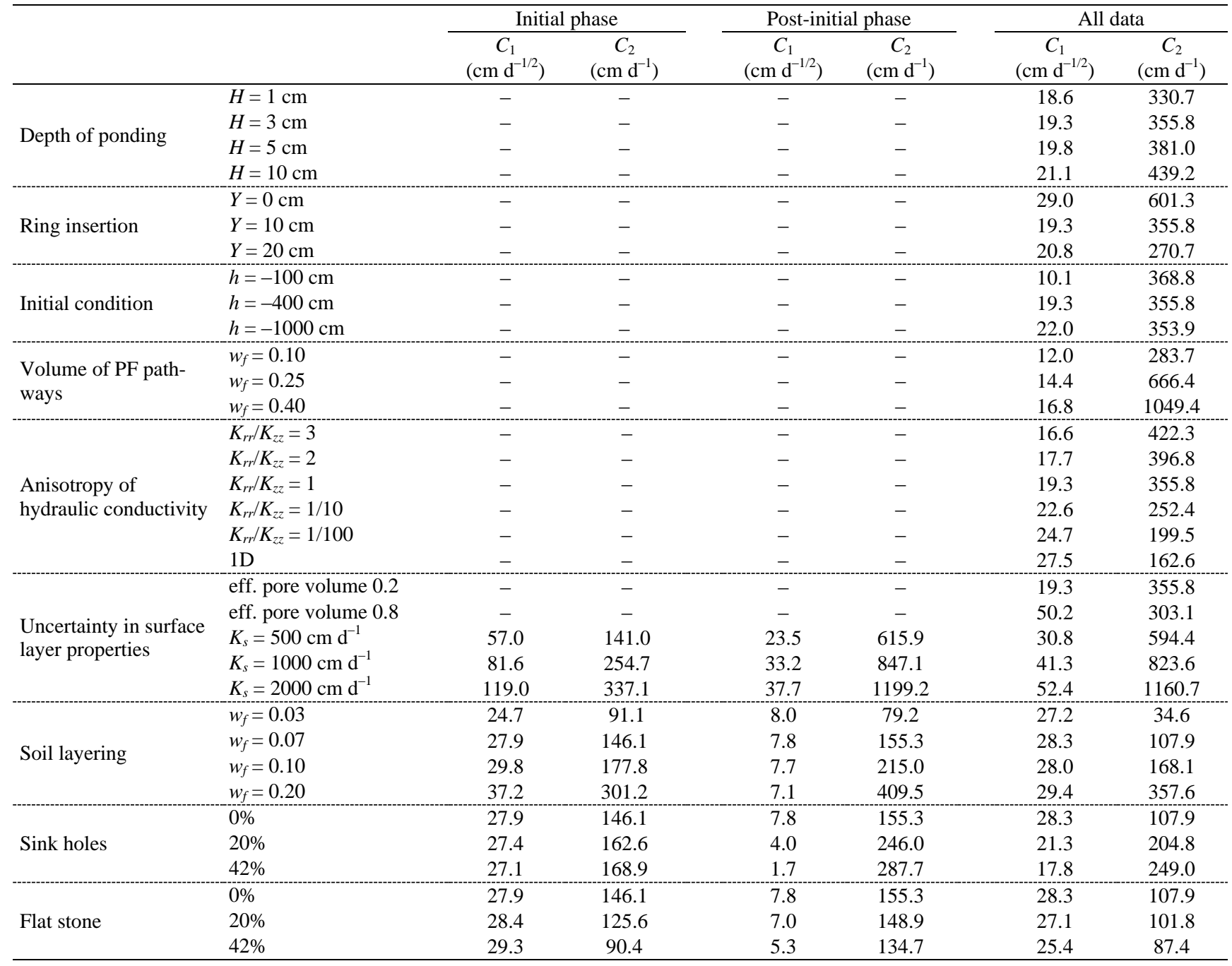


a)

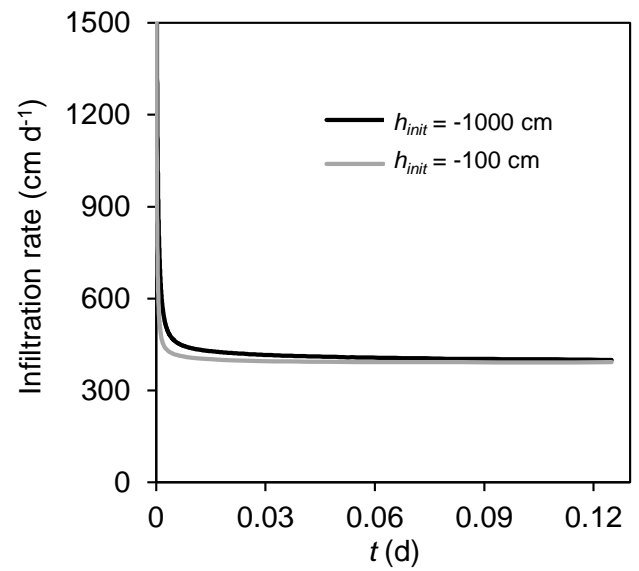

b)

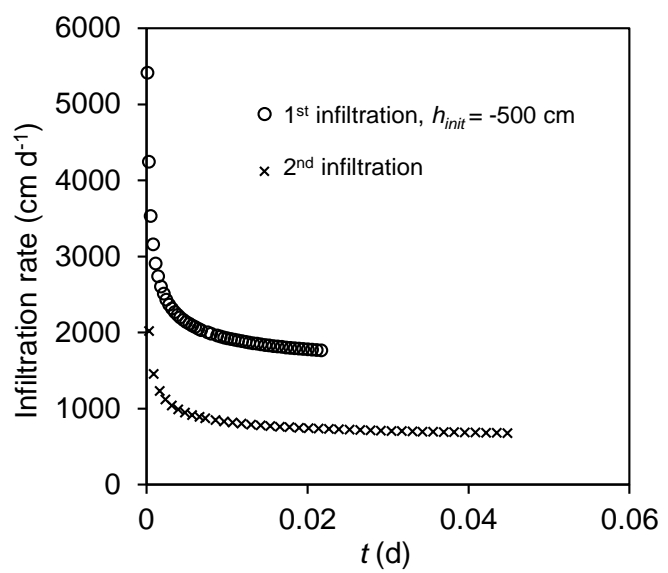

Fig. 6. (a) Infiltration rates simulated using the Richards' equation (i.e., neglecting the impact of soil air), (b) data affected by the presence of entrapped air. Two subsequent ponded infiltration experiments measured on $16^{\text {th }}$ and $17^{\text {th }}$ of July, 2007 in the ring No. 10 are displayed. The total duration of the interruption was 21 hours.

\section{Volume of preferential pathways}

In our third numerical experiment, the relative volumetric proportion of the PF-domain was varied between 3\% and 40\%, choosing $w_{f}$ in Eqs. (6) and (7) equal to 0.03, 0.1, 0.2, 0.25, and 0.4 . The simulated infiltration rates were then compared with the measured infiltration curves at Liz (Fig. 7). Variation of infiltration data (ring No. 16 in 2003, 2004, and 2006) seem to be adequately described by relatively large volumes of PFdomain (from 10 to 40\%). Lower PF-domain volumes (up to $10 \%$; not shown here) produce a similar spread of infiltration curves as obtained by varying the depth of ponding in the infiltration ring (Fig. 4a). Another important aspect of the results shown in Fig. 7 is related to different values of $C_{1}$ coefficient (i.e., the intercept in the linearized projections). The variation of the PF-domain volume could describe well the observed changes of the infiltration rates (i.e., the curve slope in Fig. 7), however, the value of $C_{1}$ remains to a large degree unexplained.

\section{Anisotropy of soil hydraulic conductivity}

The effect of introducing anisotropy of hydraulic conductivity (changing $K_{r r} / K_{z z}$ ratio while $K_{z z}$ remains constant) is illustrated in Fig. 8. In the linearized projection, decreasing $K_{r r}$ (cases with $K_{r r} / K_{z z}<1$, Fig. 8a) leads to less bent infiltration curve. This is due to restricted development of threedimensional water flow below the bottom edge of the infiltration ring. The simulations with strongly decreased horizontal conductivity thus resembled one-dimensional infiltration.

Increasing horizontal hydraulic conductivity (cases with $K_{r r} / K_{z z}>1$, Fig. 8b), produced similar changes in the slope of the linearized infiltration curves as those induced by variation of the PF-domain volume (for changes in $w_{f}$ of a few percent). The difference between varying anisotropy and PF-volume scenarios is that the increased anisotropy did not affect flow within inserted part of the infiltration ring while increased volume of preferential pathways had the effect on infiltration results during the entire experiment (compare early times of infiltration in Fig. 7 and Fig. 8).

\section{Surface organic layer properties}

As stated above, the hydraulic properties of the surface organic layer are highly uncertain and possibly changing in time (with changing moisture content). In our study, uncertainty of the soil water retention and the hydraulic conductivity is considered. The original effective pore volume of the surface organic layer in the soil matrix domain was 0.2 (see the $2^{\text {nd }}$ layer of the SM-domain in Table 1). When increasing the effective pore volume of the surface layer to 0.8 , the intercept in the linear projections of infiltration data, $C_{1}$ increased by $35 \mathrm{~cm} \mathrm{~d}^{-1 / 2}$ (Fig. 9a). However, $C_{1}$ coefficients evaluated for the measured infiltration curves varied by $493.5 \mathrm{~cm} \mathrm{~d}^{-1 / 2}$. Thus, it becomes clear that the wide range of $C_{1}$ values derived from measured infiltration curves cannot be explained by the increased effective retention pore volume only.

Increasing the saturated hydraulic conductivity of the surface layer amplifies the hydraulic contrast in respect to the second layer, which is manifested by a momentary decrease in the projected cumulative infiltration rates in the differential linear projection (Fig. 9b). It also significantly increases the "initial" $C_{1}$ values (from 57 to $119 \mathrm{~cm} \mathrm{~d}^{-1 / 2}$, Table 3 ) while it shortens the initial stage of vertical 1D infiltration within the ring. This effect is further examined in the following section together with the impact of the heterogeneous soil profile.

\section{Soil layering}

The effect of soil layering is shown in Fig. 10. Distinctly different hydraulic properties of the surface organic layer and less conductive second layer caused departure from a straight line in the linearized projection. In Fig. 10a, the effect of soil layering is coupled with the effect of varying volume of preferential pathways. The simulations are confronted with the observed infiltration at the ring No. 4 (Fig. 10b). Simulated and observed infiltration series are characterized by a notable decrease, occurring at different time (17.1 and $1.6 \mathrm{~min})$. From this timing difference (approx. $15 \mathrm{~min}$ ) between simulations and measurements, it follows that the real and model systems have different surface layer properties (thickness, porosity, and/or hydraulic conductivity).

\section{Sink holes}

The effect of a sink hole below the infiltration ring is shown in Fig. 11. Considering a sink hole within the first layer reduces the effect of the second layer on the infiltration process. The soil layering effect on the shape of infiltration curves in the 
a)

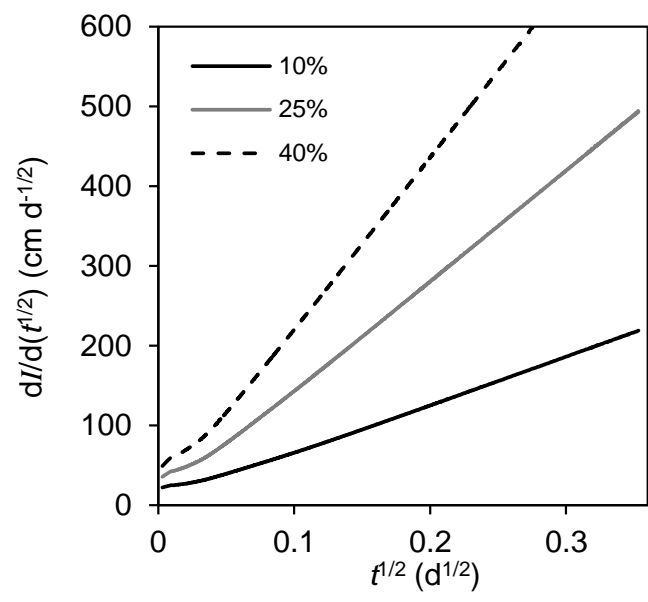

b)

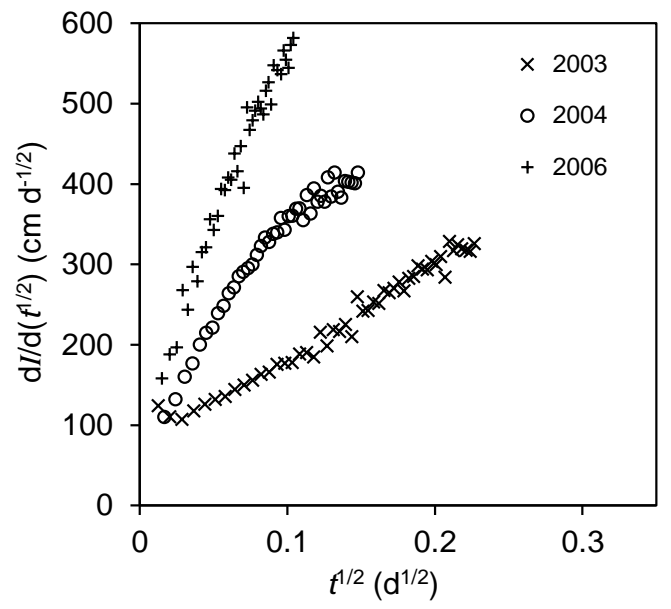

Fig. 7. (a) Simulated infiltration rates assuming three different volumes of preferential pathways $w_{f}$, (b) infiltration data from the ring No. 16 measured in three selected years.

a)

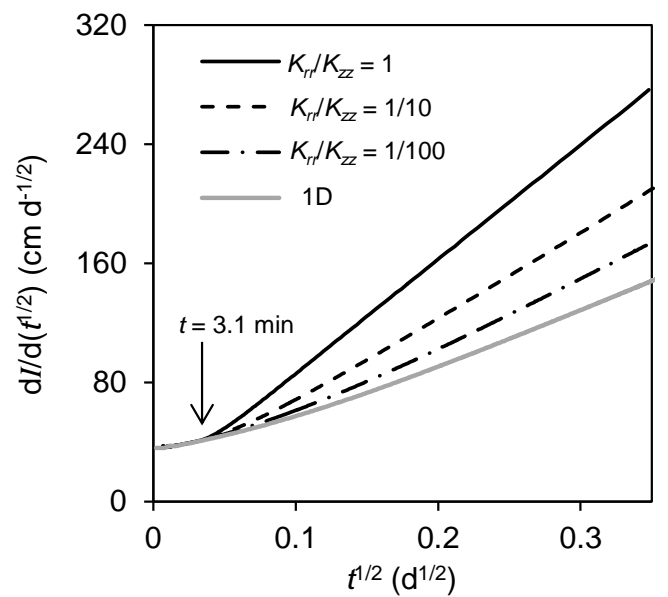

b)

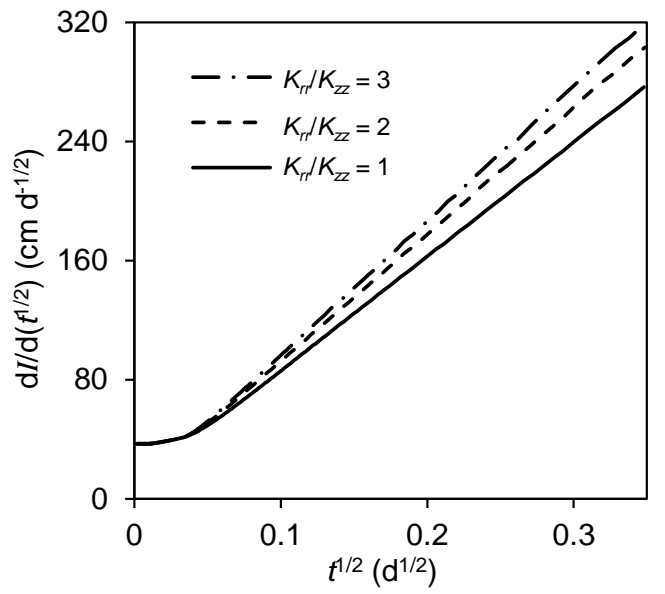

Fig. 8. Simulation results for scenarios assuming different anisotropy ratio of hydraulic conductivity $\left(K_{r r} / K_{z z}\right)$; (a) $K_{r r} / K_{z z} \leq 1$ and (b) $K_{r r} / K_{z z}$ $\geq 1$. 3D simulation results converge to $1 \mathrm{D}$ for infiltration area $D=\infty$. Wetting front reaches the bottom edge of the infiltration ring at $3.1 \mathrm{~min}$ after the beginning of infiltration.

a)

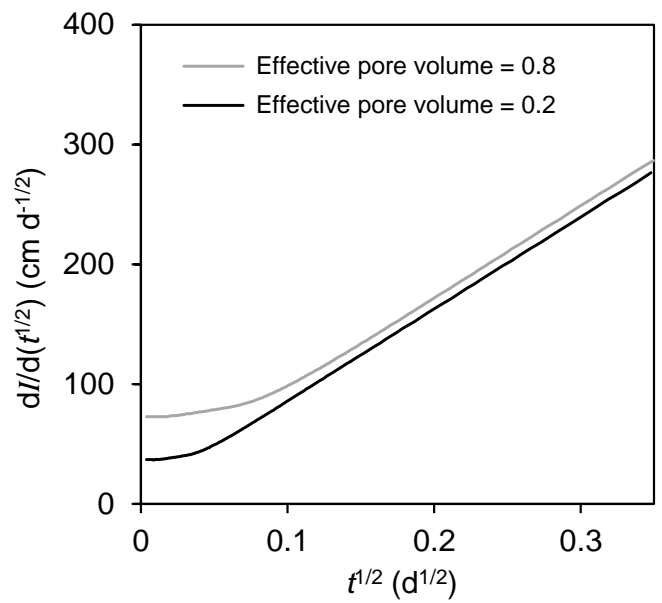

b)

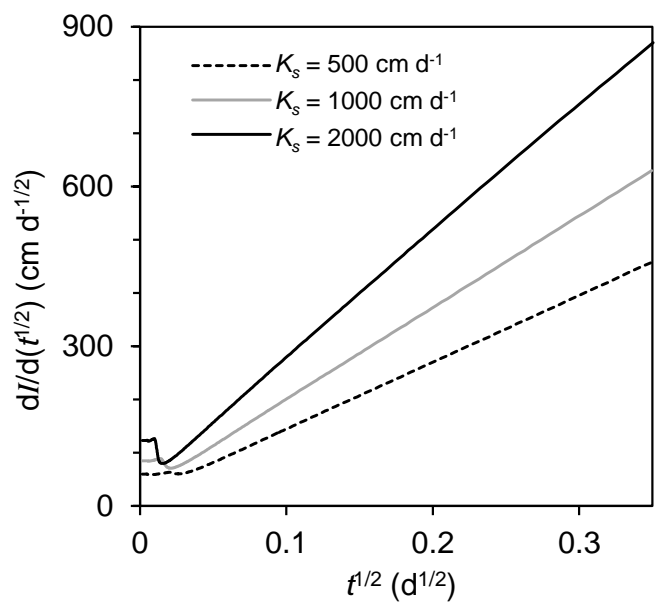

Fig. 9. Simulation results for (a) increased effective pore volume and (b) increased value of saturated hydraulic conductivity of surface layer. 
a)

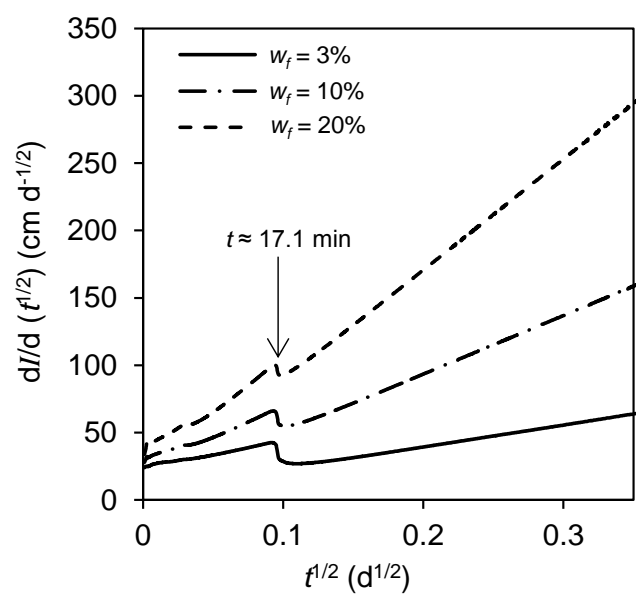

b)

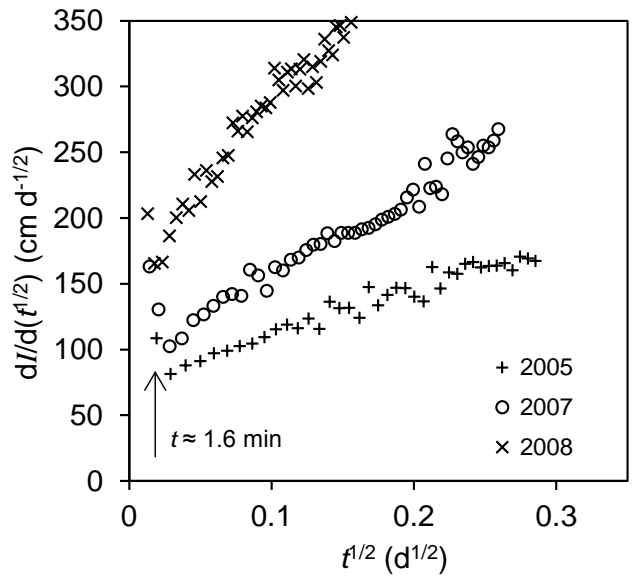

Fig. 10. Infiltration curves demonstrating the shape effect of hydraulically contrasting soil layers; (a) simulation results considering different volumes of preferential pathways $w_{f}$, (b) experimental data measured at the ring No. 4 .

initial phase of infiltration (departure from a straight line) is thus significantly reduced (20 and $42 \%$ curves vs. $0 \%$ curve in Fig. 11a). Cumulative infiltration at three hours increased to 33 or $38 \mathrm{~cm}$ depending on the areal extent of the sink hole $(20$ or $42 \%$ of the ring area).

\section{Flat stone}

The presence of a flat stone below the infiltration ring is examined in Fig. 12. A lower slope of the linearized infiltration curve indicates lower hydraulic conductivity of the soil system. Soil water pressure head fields during both the sink hole (Fig. 11b) and the flat stone (Fig. 12b) scenarios are very similar. However, the amount of water infiltrated is considerably different (compare Fig. 11a with Fig. 12a). Cumulative infiltration at three hours was 23 or $20.6 \mathrm{~cm}$ depending on the areal extent of the flat stone ( 20 or $42 \%$ of the ring area). Unaffected scenario " $0 \%$ " is identical with that in Fig. 11.

\section{Variability of the coefficients $C_{1}$ and $C_{2}$}

Coefficients $C_{1}$ and $C_{2}$ evaluated for the simulated infiltration curves resulting from all simulation scenarios performed are summarized in Table 3. When a distinct departure from a straight line is encountered in the linearized projection due to soil layering, coefficients $C_{1}$ and $C_{2}$ for both separate parts of data - before and after the change of slope - are provided as well. Table 3 reveals the large variability of the coefficients $C_{1}$ and $C_{2}$ caused by different hydraulic and structural factors included in our analysis.

The value of $C_{1}$ was most affected by varying the saturated hydraulic conductivity of the surface layer. The largest change of $C_{2}$ value was induced by varying the volume of preferential flow pathways.

Values of $C_{1}$ obtained for the numerical experiment with varying anisotropy show decreasing trend with increasing anisotropy ratio $K_{r r} / K_{z z}$ (see Table 3 ). This is due to the effect of the infiltration ring insertion.

In the single-continuum simulations with homogeneous soil profile (i.e., numerical experiments with the varying depth of ponding, ring insertion, and initial condition), the true (model) value of $K_{s}$ is $205 \mathrm{~cm} \mathrm{~d}^{-1}$ (see Table 1) and the true (model) sorptivity value is $32.8 \mathrm{~cm} \mathrm{~d}^{-1 / 2}$ (determined using a horizontal 1D infiltration simulation for $h=-400 \mathrm{~cm}$ ). The values of $C_{2}$ coefficient obtained from the numerical experiments (Table 3) vary from 132 to $293 \%$ of the true $K_{s}$ value. Similarly, the fitted $C_{1}$ coefficient for numerical experiments including depth of ponding and ring insertion varies between 57 and $88 \%$ of the true $S$ value. Underestimation of $S$ even in the case without any ring insertion is due fitting long-time infiltration data. Further decrease of fitted $C_{1}$ values is related to combined fitting of 1D (within the ring) and 3D (below the ring) stages of the experiment. In all experiments, the y-intercept of the linearized infiltration curves indicates a value close to the true sorptivity of the surface layer.

For numerical experiment considering uncertainty in surface layer properties, the determined values of $C_{2}$ (Table 3) correspond to $0.28 K_{s}, 0.25 K_{s}$, and $0.17 K_{s}$ for the surface layer $K_{s}$ set to 500,1000 , and $2000 \mathrm{~cm} \mathrm{~d}^{-1}$, respectively. Low values of $C_{2} / K_{s}$ ratios are related to water flow during the initial phase of the numerical experiment which has strictly 1D character, i.e. water flows vertically within the inserted part of the infiltration ring. However, determined ratios slightly differ from interval $(0.33-0.66) K_{s}$ suggested by Talsma and Parlange (1972).

\section{Further relevance to the measured data at $\mathrm{Liz}$}

The natural variability of experimental data was relatively well explained by numerical simulations with varying experimental conditions and simulations based on the dual- continuum concept. However, the range of intercepts in the linearized projections of individual numerical experiments, when compared with the intercept range of the measured experiments, was found to be too small. Neither the varied experimental conditions, nor the tested soil profile properties were able to fully explain the enormous spatiotemporal variability of shapes and scales of the measured infiltration curves. This is partly due to the fact that real soil system is still more complex than its model representation and a combination of several different effects should be considered. For example, when combining increased conductivity of surface organic layer with sink holes in layered heterogeneous soil profile containing large volume of preferential pathways the model might be capable of generating infiltration curves similar to curves observed at Liz (not shown here). Another potentially important effect is the air entrapment which was not included in our simulations (see Fig. 6b). 
a)

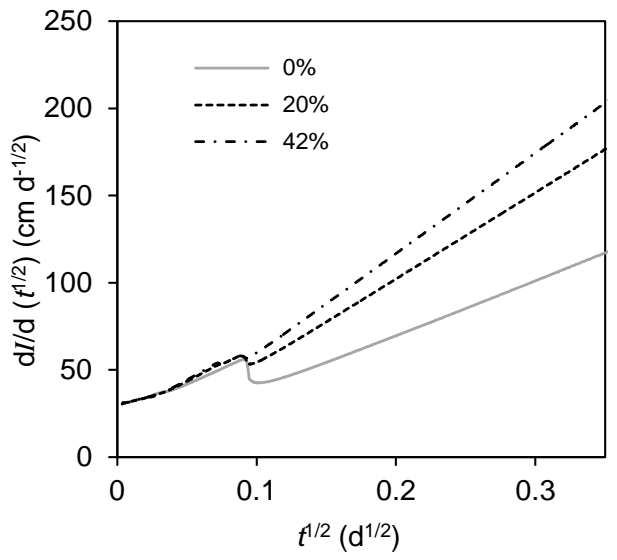

b)

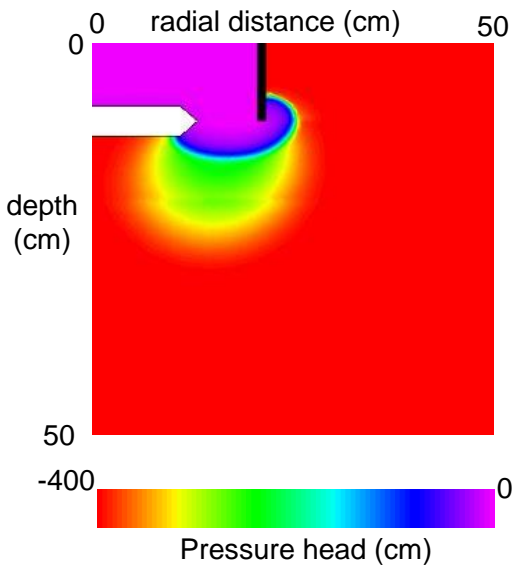

Fig. 11. Simulation results (a) for scenarios assuming different areal extent of sink holes below infiltration ring. $42 \%, 20 \%$ and $0 \%$ of the ring area is treated as a sink hole. (b) Soil water pressure head in the vertical axial plane at $t=14.4$ min in the soil matrix $(50 \times 50 \mathrm{~cm}$ detail) for the " $42 \% "$ scenario.

a)

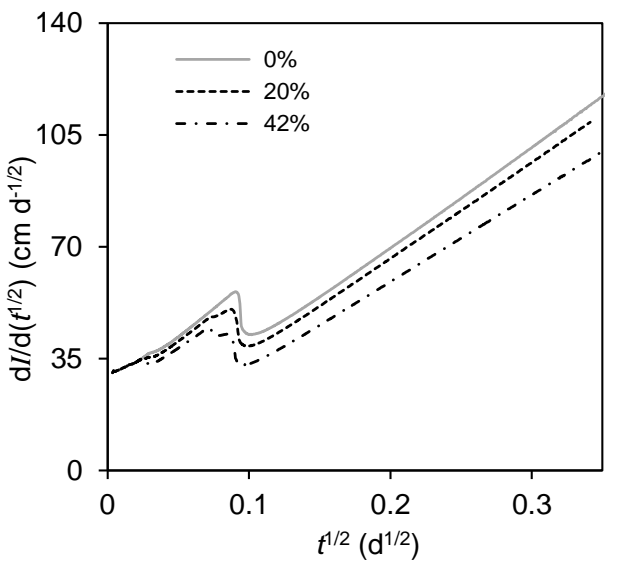

b)

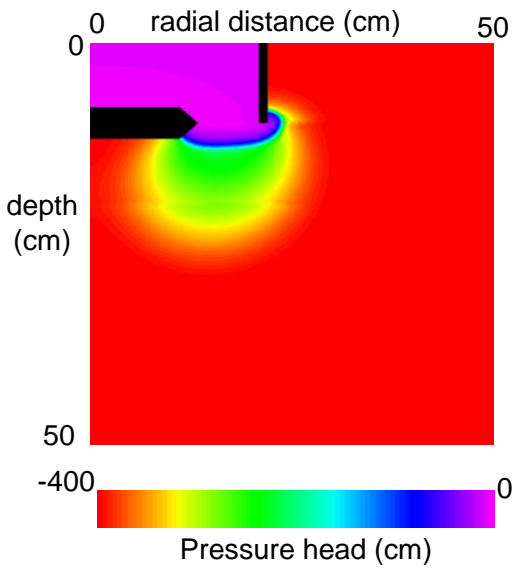

Fig. 12. Simulation results assuming a flat stone below the infiltration ring. (a) Three scenarios involving: $42 \%, 20 \%$ and $0 \%$ of the ring area treated as a flat stone. (b) Soil water pressure head in the vertical axial plane at $t=14.4 \mathrm{~min}$ in the soil matrix $(50 \mathrm{x} 50 \mathrm{~cm}$ detail) for the " $42 \%$ " scenario.

\section{CONCLUSIONS}

Numerical modeling was used to identify possible causes of the significant spatiotemporal variability of measured infiltration curves at a small experimental plot. The applied threedimensional axisymmetric dual-continuum model of soil water flow allowed a detailed analysis of diverse and often overlooked factors affecting the results of in-situ ponded infiltration experiments.

The dual-continuum model was able to describe part of the variability of infiltration curves associated with soil structure heterogeneity. However, none of the tested factors could explain infiltration rates caused by complex system of tunnels and burrows at plot scale or wide range of $C_{1}$ values derived from measured infiltration curves. Nevertheless, better agreement between simulated and observed infiltration characteristics could be achieved by combining several of these factors. Specifically, increased conductivity of surface organic layer combined with large sink hole and significant volume of preferential pathways was able to explain $C_{1}$ values determined from the measured data.

As shown in this study, $C_{1}$ or sorptivity values obtained from ponded infiltration experiment, performed on structured hetero- geneous soil, will be associated with high degree of uncertainty. The determination of $C_{2}$ or saturated hydraulic conductivity values is seriously complicated by the ring insertion effect.

Still, in most cases, determined $C_{2}$ coefficient values seem to be applicable as an estimate of $K_{s}$ with the precision in an order of magnitude. Considering homogeneous soil profile, the values of $C_{2}$ coefficient acquired from the numerical experiments imitating the impact of experimental setup and initial conditions varied from 132 to $293 \%$ of the true $K_{s}$ value. Similar $C_{2} / K_{s}$ ratios were obtained in scenarios introducing the preferential pathways (considering combined conductivity of PF- and SMdomains) or hydraulic conductivity anisotropy; except cases with reduced horizontal conductivity when $C_{2} / K_{s}$ ratios get lower $\left(C_{2} / K_{s}=0.79\right.$ for $1 \mathrm{D}$ simulation $)$. Considering scenarios with layered soil profile, $C_{2}$ values obtained based on fulllength infiltration curves provided similarly effective estimate of the hydraulic conductivity related to the mineral soil below the surface layer. Higher $C_{2} / K_{s}$ ratios (above 3 ) were obtained only in the scenario with increased surface layer conductivity and in the case with large sink hole below the infiltration ring.

The results of our analysis also suggest that the experimental conditions should be carefully recorded to make a correct interpretation of infiltration data possible. For example, a similar 
change of the infiltration curve can result either from varying the depth of ponding or from small changes in the volumetric proportion of the preferential pathways.

Acknowledgement.This study was supported by the Czech Science Foundation, Project No. 14-03691S.

\section{REFERENCES}

ASTM Standard D3385-09, 2009. Standard Test Method for Infiltration Rate of Soils in Field Using Double-Ring Infiltrometer. West Conshohocken, PA, www.astm.org.

Bagarello, V, Iovino, M., Lai, J., 2013. Field and numerical tests of the two ponding depth procedure for analysis of single-ring pressure infiltrometer data. Pedosphere, 2, 779-789.

Cislerova, M., Simůnek, J., Vogel, T., 1988. Changes of steadystate infiltration rates in recurrent ponding infiltration experiments. J. Hydrol., 104, 1-16.

Dohnal, M., Dušek, J., Vogel, T., Císlerová, M., Lichner, L., Štekauerová, V., 2009. Ponded infiltration into soil with biopores - field experiment and modeling. Biologia, 64, 580 584.

Dohnal, M., Dusek, J., Vogel, T., 2010. Improving hydraulic conductivity estimates from minidisk infiltrometer measurements for soils with wide pore-size distributions. Soil Sci. Soc. Am. J., 74, 804-811.

Dohnal, M., Jelinková, V., Snehota, M., Dusek, J., Brezina, J., 2013. Three-dimensional numerical analysis of water flow affected by entrapped air: application of noninvasive imaging techniques. Vadose Zone J., 12, 1, DOI: 10.2136/vzj2012.0078

Dusek, J., Dohnal, M., Vogel, T., 2009. Numerical analysis of ponded infiltration experiment under different experimental conditions. Soil \& Water Res., 4, S22-S27.

Ganz, Ch., Bachmann, J., Noell, U. et al., 2014. Hydraulic modeling and in situ electrical resistivity tomography to analyze ponded infiltration into a water repellent sand. Vadose Zone J., 13, 1, DOI:10.2136/vzj2013.04.0074

Gerke, H.H., van Genuchten, M.Th., 1993. A dual-porosity model for simulating the preferential movement of water and solutes in structured porous media. Water Resour. Res., 29, 305-319.

Haverkamp, R., Ross, P.J., Smettem, K.R.J., Parlange, J.-Y., 1994. Three dimensional analysis of infiltration from the disc infiltrometer: 2. Physically-based infiltration equation. Water Resour. Res., 30, 2931-2935.

Hillel, D., 1998. Environmental Soil Physics. Elsevier Academic Press, San Diego, CA, USA.

Hogarth, W.L., Lockington, D.A., Barry, D.A., Parlange, M.B., Haverkamp, R., Parlange, J.Y., 2013. Infiltration in soils with a saturated surface. Water Resour. Res., 49, 5, 2683 2688.

Johnson, A.I., 1963. A field method for measurement of infiltration. General ground-water techniques. Geological Survey Water-Supply Paper 1544-f.

Miller, E.E., Klute, A., 1967. The dynamics of soil water. Part I - mechanical forces. In: Hagan, R.M., Haise, H.R, Edminster, T.W. (Eds.): Irrigation of Agricultural Lands. Am. Soc. Agron., Madison, WI, USA, pp. 209-244.

Mirus, B.B., Perkins, K.S., Nimmo, J.R., Singha, K., 2008. Hydrologic characterization of desert soils with varying degrees of pedogenesis: 2. Inverse modeling for effective properties. Vadose Zone J., 8, 496-509.
Nakhaei, M., Šimůnek, J., 2014. Parameter estimation of soil hydraulic and thermal property functions for unsaturated porous media using the HYDRUS-2D code. J. Hydrol. Hydromech., 62, 1, 7-15.

Nimmo, J.R., 2012. Preferential flow occurs in unsaturated conditions. Hydrol. Process., 26, 786-789.

Philip, J.R., 1954. Some recent advances in hydrologic physics. J. Inst. Engrs. Australia, 26, 255-259.

Philip, J.R., 1957. The theory of infiltration: 4. Sorptivity and algebraic infiltration equations. Soil Sci., 84, 257-284.

Šimůnek, J., 1988. Infiltration - numerical simulation. Vodohospodársky Časopis, 36, 407-420. (In Czech.)

Smettem, K.R.J., Parlange, J.-Y., Ross, P.J., Haverkamp, R., 1994. Three dimensional analysis of infiltration from the disc infiltrometer: 1. A capillary based theory. Water Resour. Res., 30, 2925-2929.

Smiles, D.E., Knight, J.H., 1976. A note on the use of the Philip infiltration equation. Aust. J. Soil Res., 10, 143-150.

Talsma,T., Parlange, J.-Y., 1972. One-dimensional infiltration. Aust. J. Soil Res., 10, 143-150.

Turner, N.C., Parlange, J.-Y., 1974. Lateral movement at the periphery of a one-dimensional flow of water. Soil Sci., 118, 70-77.

Vandervaere, J.-P., Peugeot, C., Vauclin, M., Angulo-Jaramillo, R., Lebel, T., 1997. Estimating hydraulic conductivity of crusted soils using disc infiltrometers and minitensiometers. J. Hydrol., 188-189, 203-223.

van Genuchten, M.Th., 1980. A closed-form equation for predicting the hydraulic conductivity of unsaturated soils. Soil Sci. Soc. Am. J., 44, 892-898.

Vogel, T., Gerke, H.H., Zhang, R., van Genuchten, M.Th., 2000. Modelling flow and transport in a two dimensional dual-permeability system with spatially variable hydraulic properties. J. Hydrol., 238, 78-89.

Vogel, T., van Genuchten, M.Th., Císlerová, M., 2001. Effect of the shape of soil hydraulic functions near saturation on variably-saturated flow predictions. Advances in Water Resources, 24, 133-144.

Votrubova, J., Jelinkova, V., Nemcova, R., Tesar, M., Vogel, T., Cislerova, M., 2010. The soil apparent infiltrability observed with ponded infiltration experiment in a permanent grid of infiltration rings. Geophysical Research Abstracts, Vol. 12, EGU2010-11898.

Votrubova, J., Dohnal, M., Vogel, T., Tesař, M., 2012. On parameterization of heat conduction in coupled soil water and heat flow modelling. Soil \& Water Res., 7, 125-137.

Wang D., Feyen J., van Genuchten, M.Th., Nielsen, D.R., 1998. Air entrapment effects on infiltration rate and flow instability. Water Resour. Res., 34, 213-222.

Wang, C., Mao, X., Hatano, R., 2014. Modeling ponded infiltration in fine textured soils with coarse interlayer. Soil Sci. Soc. Am. J., 78, 745-753.

White, I., Sully, M., 1987. Macroscopic and microscopic capillary length and time scales from field infiltration. Water Resour. Res., 23, 1514-1522.

Zhang, R. 1997. Determination of soil sorptivity and hydraulic conductivity from the disk infiltrometer. Soil Sci. Soc. Am. J., 61, 1024-1030.

Received 25 November 2015 Accepted 2 March 2016 